UNITED STATES DEPARTMENT OF THE INTERIOR

GEOLOGICAL SURVEY

An Example Expert System for the Interpretation of

Depositional Environments

by

Katherine B. Krystinik ${ }^{1}$

Open-File Report 85-30

This report is preliminary and has not been reviewed for conformity with U.S. Geological Survey editorial standards and stratigraphic nomenclature.

1 Denver, Co 


\section{CONTENTS}

Page

Abstract $\ldots \ldots \ldots \ldots \ldots \ldots \ldots \ldots \ldots \ldots \ldots \ldots \ldots \ldots \ldots \ldots \ldots \ldots \ldots \ldots \ldots \ldots$

Introduction ..................................... 1

Discussion..................................... 2

Conclusions..................................... 4

Acknowledgments $\ldots \ldots \ldots \ldots \ldots \ldots \ldots \ldots \ldots \ldots \ldots \ldots \ldots \ldots \ldots \ldots \ldots \ldots \ldots$

References....................................... 5

Appendix A..................................... 6

Appendix B......................................... 10

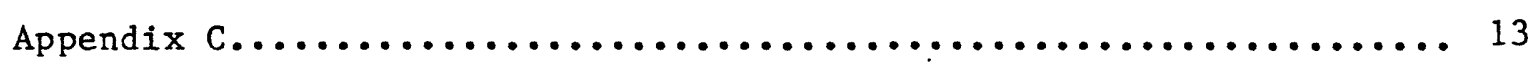

\section{ILLUSTRATIONS}

Page

1. Inference network.............................. 3 


\title{
AN EXAMPLE EXPERT SYSTEM FOR COMPUTER INTERPRETATION OF DEPOSITIONAL ENVIRONMENTS
}

by

\author{
Katherine B. Krystinik
}

\begin{abstract}
Expert Systems can be applied to the interpretation of sedimentary depositional environments by comparing the distinguishing features of the environments to the characteristics of a core or an outcrop. An example Expert System has been constructed which determines whether an outcrop or a core under consideration is consistent with shelf sands deposition. This rule-based system was constructed using the Knowledge Acquisition System developed by SRI International and is easily used. This example system indicates that Expert Systems for determining depositional environments are useful for teaching as well as consulting. These Expert Systems will increase the availability and applicability of sedimentological classifications. As educational tools, these systems demonstrate the progressive logic of an expert in solving a problem, as well as providing ready access to reference material.
\end{abstract}

\section{INTRODUCTION}

Expert Systems are a result of applied research in Artificial Intelligence. They have been used to predict the location of mineral deposits (Duda, Hart, Konolige, Reboh, 1979), diagnose diseases (Shortliffe, 1975), and to perform many other functions requiring expertise. Both the factual and heuristic knowledge of an expert is incorporated into an Expert System. Factual knowledge is found in textbooks; heuristic knowledge is the intuitive or "rules-of-thumb" understanding that is gained from years of specialized work.

The Expert System described here was constructed on a VAX-780 ${ }^{1}$ using the Knowledge Acquisition System (KAS) developed by Stanford Research Institute. In the Expert System knowledge is represented as an inference network (Figure 1). In the inference network, pieces of evidence are combined to form other pieces of evidence and, subsequently, to form hypotheses. Evidence can be assembled through logical combinations (and, or, not), through plausible inference, and through contexts. An example of a logical combination is shown in figure 1: if a piece of evidence $E_{1}$ and a piece of evidence $E_{2}$ are true, then evidence $E_{3}$ is true. Plausible inference is of the type

A piece of evidence $\mathrm{E}$ suggests a hypothesis $\mathrm{H}$ with strength $\mathrm{S}$.

A piece of evidence $E$ can be highly or only slightly suggestive of the hypothesis $\mathrm{H}$. Contexts (depicted by the dashed line between $\mathrm{E}_{2}$ and $\mathrm{E}_{4}$ ) indicate that $E_{4}$ will be asked about only if $E_{2}$ is present or if the certainty associated with ${ }^{4} \mathrm{E}_{2}$ is in the appropriate range. Contexts make the system Use of trade names in this report is for descriptive purposes only and does not constitute endorsement by the U.S. Geological Survey. 
more effective and more pleasant for the user. For example, if $\mathrm{E}_{2}$ represents the presence of burrows in a sedimentary sequence and $E_{4}$ indicates that the amount of burrowing decreases upward in the sequence, $E_{2}^{4}$ is a context for $E_{4}$. It is logical to ask whether burrowing decreases upward only if burrowing has been confirmed in the sequence.

This system uses a backward chaining control strategy for determining which questions the user is asked. This means that the system works backward from a hypothesis it. is considering to obtain the pieces of evidence which pertain to the hypothesis. The set of questions asked by the system varies from interaction to interaction. Answers to earlier questions determine the character of later questions. An example of this is the use of contexts, as described previously. The system also uses certainty factors to represent belief in pieces of evidence, prior probabilities for each piece of evidence or hypothesis, and an inference mechanism based mainly on Bayesian probability theory (Reboh, 1981).

\section{DISCUSSION}

The example Expert System described here determines if a particular outcrop or core indicates the depositional environment of a marine shelf sand. The system uses sedimentational sequences and structures and other information to determine the certainty that strata were deposited on a marine shelf. This system is an example of what can be done using Artificial Intelligence techniques to predict depositional environments from outcrop or core observations. The computer file containing the various nodes and connections of the inference network for this example system is in Appendix A.

Appendix B contains a sample interaction with the example expert system for shelf sands. The system asks the user to provide numerical certainties for characteristics of the outcrop or core. Certainty factors vary from -5 to $5,-5$ indicating absolute certainty that the characteristic is not present, 5 indicating absolute certainty that it is present, 0 indicating no information about the characteristic, and intermediate values indicating some certaincy (positive or negative).

Two other capabilities of the system are the "why" and "?". If the user asks "why" a certain question is being asked, the system indicates why that answer is important in determining whether the outcrop or core under consideration represents a shelf sand. If the user responds with a "?", the system rephrases the question, usually at a more basic level. The file containing the information for these functions is shown in Appendix $C$.

When the system has accumulated enough information, it provides an overall certainty that the outcrop or core reflects a shelf sand deposit. It also indicates which pieces of evidence were important in reaching the conclusion and provides the reasoning used in deriving the certainty. 


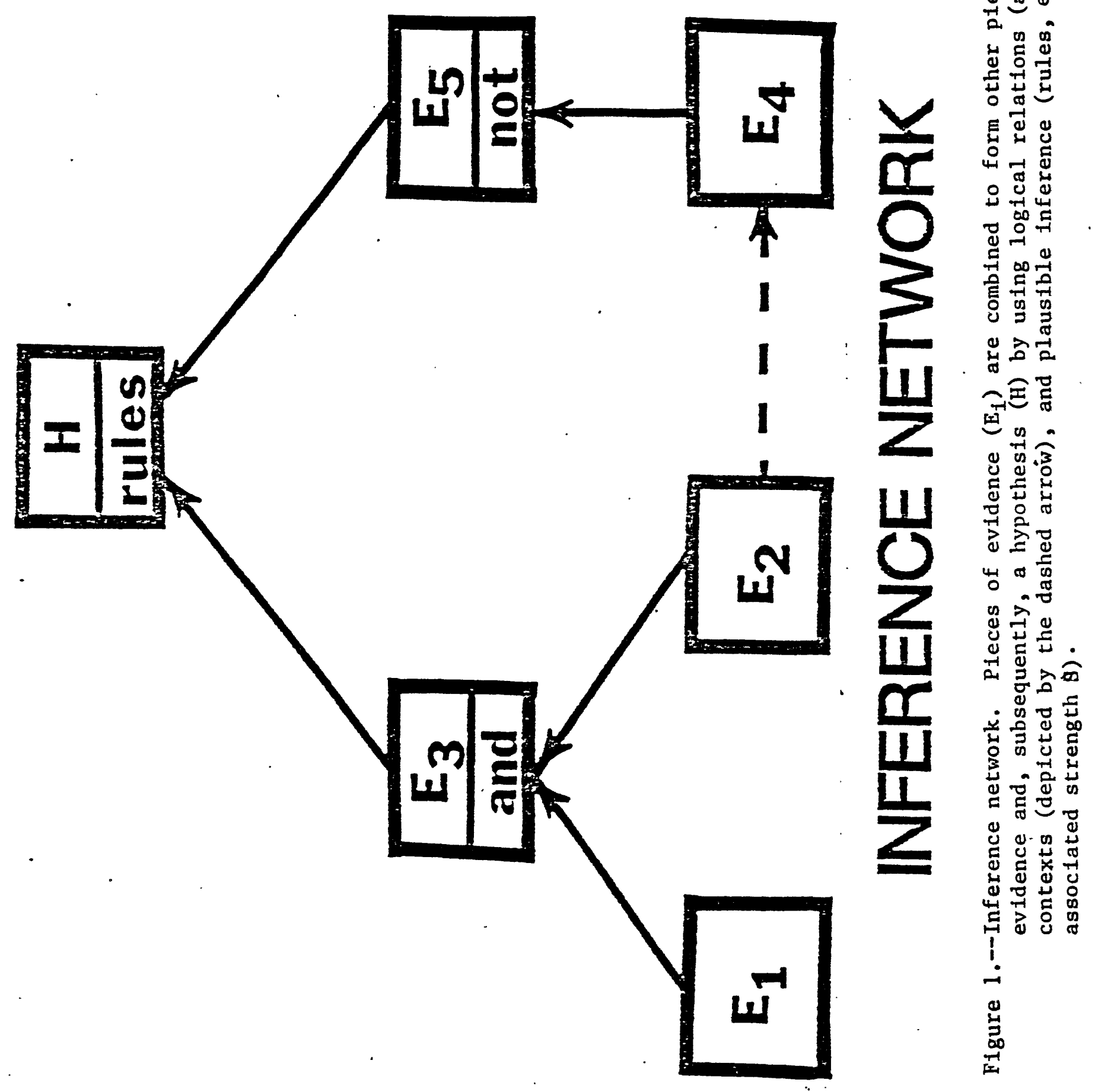




\section{CONCLUSIONS}

This example system was constructed to show the feasibility and usefulness of Expert Systems in predicting depositional environments. The availability of expertise in interpreting depositional environments allows the construction of such systems. A very useful characteristic of these systems is the separation of the inference or control mechanism from the knowledge base. This separation allows quicker and easier modification of the Expert System than if the two were intertwined.

Systems such as this example are useful for consulting and teaching. They are not intended to replace the sedimentologist, but rather to make his or her knowledge more available to the working geologist. Since references can be added easily and the why functions are present, these systems can provide rapid and easy access to reference material for any depositional environment, as well as access to an expert's procedure for identifying environments of deposition.

\section{ACKNOWLEDGMENTS}

D. L. Gautier and E. A. Merewether offered many helpful suggestions during the development of this example Expert System. R. B. McCammon taught a course on KAS and Prospector, which made learning to use KAS much easier, and he answered many questions about on the software. 


\section{REFERENCES}

Duda, R. 0., Hart, P. E., Konolige, K., and Reboh, R., 1979, A computer-based consultant for mineral exploration: SRI International final report on project $6415,185 \mathrm{p}$.

Reboh, R., 1981, Knowledge engineering techniques and tools in the prospector environment: SRI International Technical Note 243,149 p.

Shorliffe, H. E., 1975, Mycin: A rule-based computer program for advising physicians regarding antimicrobial therapy selection: Stanford University, PhD thesis, $395 \mathrm{p}$. 
Listing of the computer file containing information about the spaces (or nodes; see figure 1) of the inference network for the shelf sands example Expert System. For each space, its text description and information about its relation to other spaces is given.

model SHELF

topspace SHELF

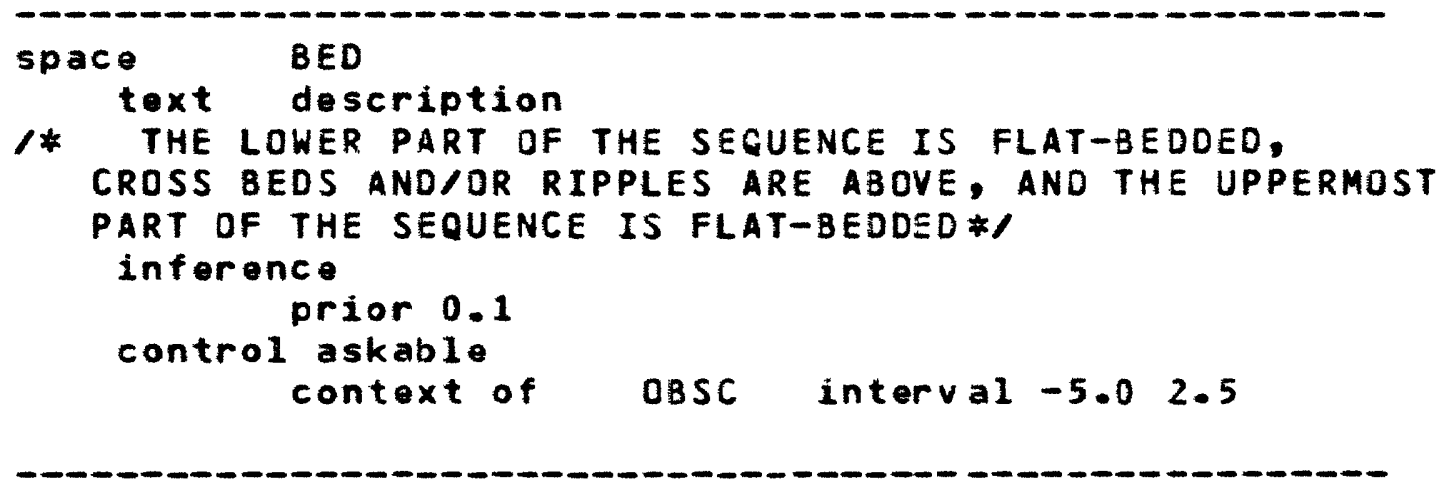

space

BIO

text description

* BURROUING IS PRESENT AND THE AMOUNT DECREASES UPWARD IN THE SEQUENCE*/

inference

prior 0.1

logical definition AND DECU PRES

control unaskable context of SEQ

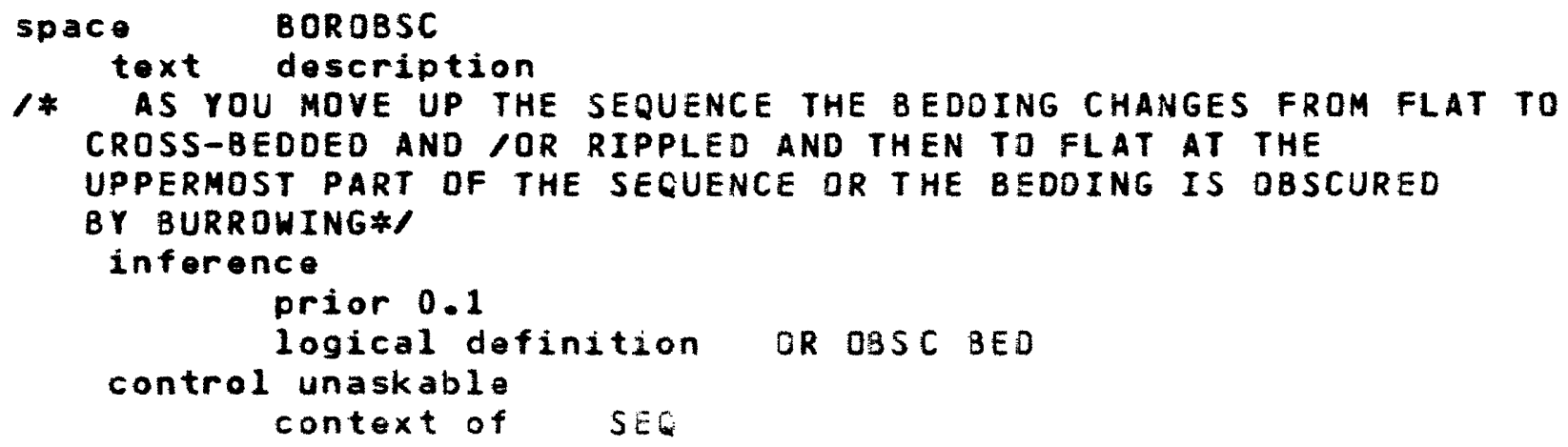


THERE ARE SOME MACRO OR MICROFOSSILS INDICATING DPEN MARINE CONDITIONS*/

inference

$$
\text { prior } 0.1
$$

control askable

space LOC

text description

1* THE LOCATION IS THAT OF A SUBMARINE SHELF */

inference

prior 0.1

logical definition AND SHORE PAR

control unaskable context of SEQ

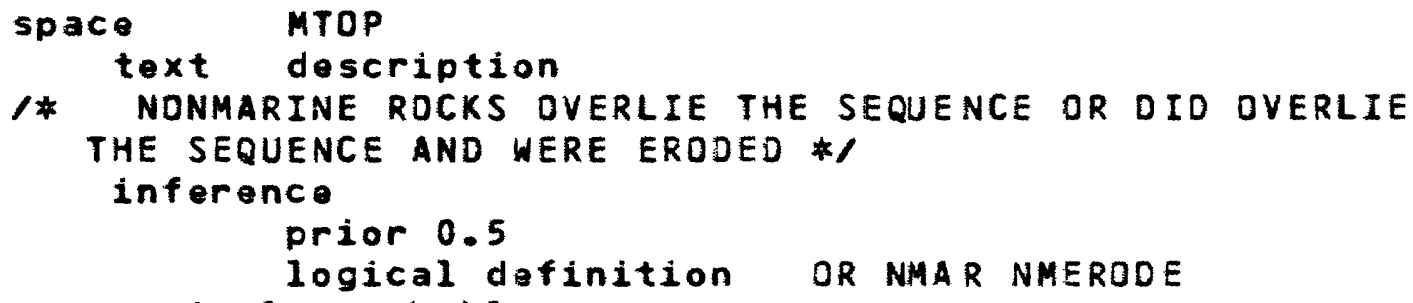

/* NDNMARINE ROCKS OVERLIE THE SEQUENCE OR DID OVERLIE THE SEQUENCE AND WERE ERODED */

inference

prior 0.5

logical definition OR NMAR NMERODE

control unaskable

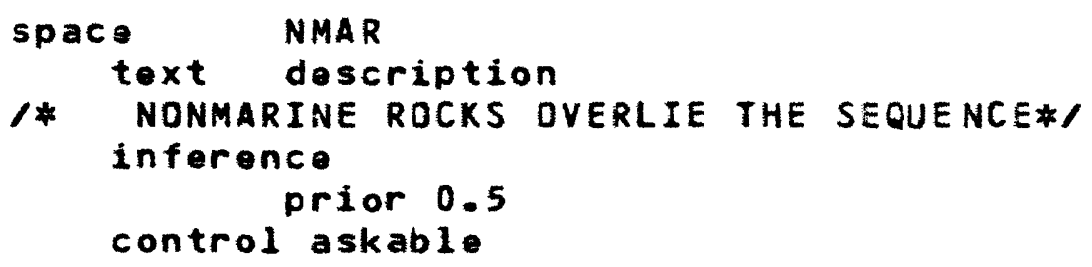




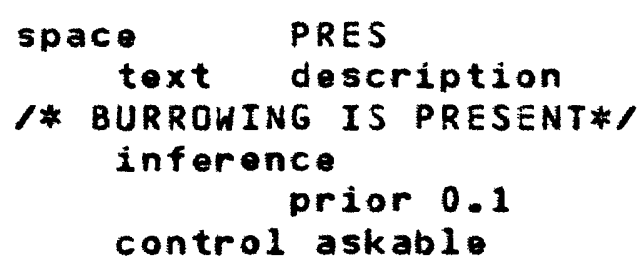

\section{space SEQ \\ text description}

* THE SEQUENCE IS COARSENING UPWARD AND CONSISTS DF SHALE, SILTSTONE, SANDSTONE AND IS NOT OVERLAIN BY RDCKS OF NONMARINE ORIGIN‡/

inference

prior 0.1

logical definition AND SHALE SILT SAND TOP control unaskable

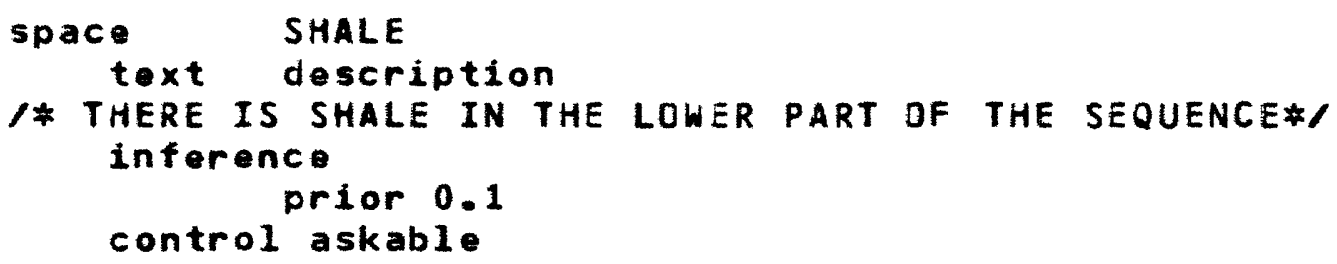

control unaskable

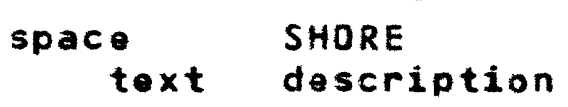


prior 0.1

control askable

space

\section{SILT}

text description

\% SILTSTONE (POSSIBLY INTERCALATED WITH SHALE) IS DIRECTLY ABOVE THE SHALE IN THE SEQUENCE*/

inference

prior 0.1

control askable

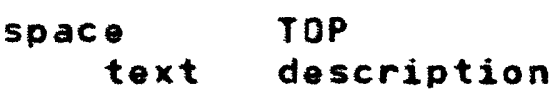

* NONMARINE ROCKS DO NOT OVERLIE THE SEQUENCE*/

inference

prior 0.5

logical definition NOT MTOP

control unaskable

STOP 
Sample interaction with the shelf sands example Expert System.

1 -- To what degreo do you believe that THERE IS SHALE IN THE LOWER PART OF THE SEQUENCE ? 4

2 -- To what degree do you beliove that SILTSTDNE (POSSIBLY INTERCALATED WITH SHALE) IS DIRECTLY ABOVE THE SHALE IN THE SEQUENCE ? 4

3 -- To what degree do you believe that SANDSTDNE (POSSIBLY INTERCALATED WITH SHALE) IS ABOVE

THE SHALE AND SILTSTONE IN THE SEQUENCE ? 4

4 -- To what degree do you believe that NONMARINE ROCKS DVERLIE THE SEQUENCE ? -4

5 -- To what degree do you believe that NONMARINE RDCKS DID OVERLIE THE SEQUENCE AND HAVE BEEN ERODED ? - 5

6 -- To what degree do you balieve that THE SHORELINE WAS MANY MILES AWAY AT TIME OF DEPDSITION ? 3

1 -- To what degree do you believe that THE SEQUENCE REPRESENTS AN ELONGATE SAND BDDY THAT WAS DEPOSITED WITHIN 30 DEGREES DF PARALLEL TO THE SHORELINE ? 3

8 -- To what degree do you believe that THERE ARE SOME MACRO OR MICRDFOSSILS INDICATING DPEN MARINE CONDITIONS? 0

9 -- To what degree do you believe that BURROWING IS PRESENT? 4

10 -- To what degree do you believe that THE AMOUNT OF BURROWING DECREASES UPWARD IN THE SEQUENCE ? WHY

BIOTURBATION DECREASING UPHARD INDI CATES

1.) DEGREE OF REWORKING BY STORM EVENTS IS INCREASING UPWARD 2.)RATE OF SEDIMENTATION IS INCREASING UPWARD. BOTH DF THESE ARE CONSISTENT WITH SHELF SAND DEPOSITS.

10 -- To what degree do you believe that THE AMOUNT DF BURROWING DECREASES UPWARD IN THE SEQUENCE ? 4

11 -- To what degree do you believe that BEDDING IS OBSCURED BY BIDTURBATION ? ?

BIOTURBATION OBSCURING THE BEDDING MEANS THAT THERE IS SO MUCH BURROWING THAT THE BED TYPES CANNOT BE DISCERNED.

To what degree do you believe that BEDDING IS OBSCURED BY BIOTURBATION ? WHY 
SUCH BIOTURBATIDN IS COMMON IN SHELF SANDS. IF BIOTURBATION DOESN T OBSCURE THE BEDDING, THE BEDDING TYPES WILL BE EXAMINED FOR CONSISTENCY WITH A SHELF SANDS MODEL.

11 -- To what degree do you believe that BEDOING IS DBSCURED BY BIOTURBATION? -1

12 -- To what degree do you boliove that THE LOWER PART DF THE SEQUENCE IS FLAT-BEDDED, CROSS BEDS AND/OR RIPPLES ARE ABOVE, AND THE UPPERMOST PART OF THE SEQUENCE IS FLAT-BEDDED ? 3

I have nothing more to ask about this hypothesis.

I suspoct that THE DUTCROP INDICATES A SHELF SAND DEPOSITIONAL MODEL (certainty 3.89142$)$.

There are several favorable factors; in order of importance:

1) THE SEQUENCE IS COARSENING UPWARD AND CONSISTS DF SHALE, SILTSTDNE, SANDSTONE AND IS NOT DVERLAIN BY ROCKS OF NONMARINE ORIGIN (cortain ty 4.0)

2) BURROWING IS PRESENT AND THE AMOUNT DECREASES UPWARD IN THE SEQUENCE (certainty 4.0)

3) THE LOCATION IS THAT OF A SUBMARINE SHELF (certainty 3.0)

4) AS YOU MOVE UP THE SEQUENCE THE BEDDING CHANGES FROM FLAT TO CROSS-BEDDED AND/OR RIPPLED AND THEN TO FLAT AT THE UPPERMOST PART OF THE SEQUENCE OR THE BEDDING IS DBSCURED BY BURROWING (certainty 3.0 )

There is one uncertain factor whose score may be subject to change:

5) You wore unsure whether THERE ARE SDME MACRC OR MICROFOSSILS INDICATING OPEN MARINE CONDITIONS (certainty $0.000000 E+00)$

For which of the above do you wish to seo additional information? (Type ? for available options) 1

On a scale from -5 to 5 , my certainty that

1: THE SEQUENCE IS CDARSENING UPWARD AND CONSISTS DF SHALE, SILTSTONE, SANDSTONE AND IS NOT DVERLAIN BY ROCKS OF NONMARINE ORIGIN is NOW 4.0 .

There are several favorable factors: in order of importance:

1: 1) NONMARINE ROCKS DO NOT OVERLIE THE SEQUENCE (certainty 4.0)

1: 2) You were suro that THERE IS SHALE IN THE LOWER PART OF THE SEQUENCE (certainty 4.0) * limiting factor *

1: 3) You were sure that SILTSTONE (POSSIBLY INTERCALATED WITH SHALE) IS DIRECTLY ABDVE THE SHALE IN THE SEQUENCE (cortainty 4.0) * limiting factor **

1: 4) You vere sure that SANDSTONE (POSSIBLY INTERCALATEO WITH SHALE) IS ABOVE THE SHALE AND SILTSTONE IN THE SEQUENCE (cortainty 4.0) * limiting factor * 
Do you wish to soe additional information about THE OUTCROP INDICATES A SHELF SAND DEPOSITIONAL MODEL? NO 
Listing of the computer file containing information for the spaces in the shelf sands example Expert System for the "why" and "?" functions.

MODEL SHELF

SPACE BED

PRDPS APPEND-DESC-TEXT T

WHY /* IN A SHELF SAND DEPOSIT CURRENT ENERGY INCREASES

UPWARD AND THEN DECREASES AT THE UPPERMDST PART

AS WOULD BE INDICATED BY THESE TYPES DF BEDDING. \#/

SPACE DECU

PROPS APPEND-DESC-TEXT T

WHY $/ *$ BIOTURBATION DECREASING UPWARD INDICATES

1.) DEGREE OF REWORKING BY STORM EVENTS IS INCREASING

UPWARD 2.)RATE OF SEDIMENTATION IS INCREASING UPWARD.

BOTH DF THESE ARE CONSISTENT WITH SHELF SAND DEPOSITS. */

SPACE FOSS

PROPS APPEND-DESC-TEXT T

WHY /* SOME FDSSIL GROUPS ARE RESTRICTED TO MARINE

ENVIRONMENTS AND MARINE CONDITIONS ARE NEEDED FOR A

SHELF SAND DEPOSIT. $* /$

SPACE NMAR

PROPS APPEND-DESC-TEXT T

WHY / * NONMARINE ROCKS OVERLYING THE SEQUENCE IS NOT

CONSISTENT WITH A SHELF SAND MODEL. */

SPACE NMERDDE

PROPS APPEND-DESC-TEXT T

? /* IF A UNIT HAS BEEN ERODED, AN ER OSIONAL SURFACE

MAY BE PRESENT. ALSO, THERE MAY BE MISSING

BIOSTRATIGRAPHIC ZONES OIRECTLY ABOVE THE SEQUENCE.*/

WHY / * NONMARINE ROCKS DVERLYING THE SEQUENCE BEFORE BEING

ERODED IS NOT CONSISTENT WITH THE DEPOSIT BEING A

SHELF SAND. \#/

SPACE OBSC

PROPS APPEND-DESC-TEXT T

$?$ ? BIOTURBATION OBSCURING THE BEDOING MEANS THAT THERE IS

SO MUCH BURROWING THAT THE BED TYPES CANNOT BE DISCERNED. *

WHY / SUCH BIOTURBATION IS COMMON IN SHELF SANDS. IF

BIOTURBATION DOESN'T OBSCURE THE BEDDING, THE BEDDING

TYPES WILL BE EXAMINED FOR CONSISTENCY WITH A SHELF SANDS

MODEL. *

SPACE PAR

PROPS APPEND-DESC-TEXT T

WHY /* MANY MODERN SHELF SAND BODIES TREND PARALLEL TO

SHORE AND THIS IS A CDMMON CHARACTERISTIC OF SHELF

SAND DEPOSITS. * 
PROPS APPEND-DESC-TEXT T

WHY / * THE REWORKING OF SEDIMENT BY ORGANISMS (BURROWING) INDICATES 1.) PROBABLE MARINE 2.)L OW ENOUGH ENERGY THAT

THE SEDIMENT COULD BE INHABITED 3 .) SSEDIMENT INPUT

THAT WAS SLOW ENOUGH TO ALLOW REWORKING BY ORGANISMS.

ALL OF THESE ARE CONSISTENT WITH SHELF DEPOSITION. *

\section{SPACE SAND}

PROPS APPEND-DESC-TEXT T

WHY / SANDS INDICATE ENERGIES HIGH ENDUGH TD ENTRAIN

SAND-SIZED DEBRIS AND WANING STDRM ENERGY CAUSING SAND

DEPOSITION. THESE WDULD BE EXPECTED IN THIS PART OF

THE SHELF SEQUENCE.

SPACE SHALE

PROPS APPEND-DESC-TEXT T

WHY /* MUDSTONE OR SILTY SHALE INDICATES LOW ENERGY DEPOSITION OFTEN REPRESENTING LONG QUIESCENT PERIODS AS HOULD BE

EXPECTED IN THE LOWER PART OF THE SHELF SAND DEPOSIT. *

SPACE SHDRE

PROPS APPEND-DESC-TEXT T

WHY $1 *$ THIS IS CONSISTENT WITH SHELF DEPOSIIION. */

SPACE SILT

PROPS APPEND-DESC-TEXT T

WHY $/$ SILTSTONE INDICATES SLIGHTLY GREATER CURRENT VELOCITIES THAN DOES SHALE, BUT STILL REPRESENTS GENERALLY QUIESCENT CONDITIONS AS WOULD BE EXPECTED AT THIS POINT IN SHELF SAND DEPOSITION. */ 